\title{
THE EVIDENCE FOR APOSTATIC SELECTION
}

\author{
BRYAN CLARKE \\ Department of Zoology, West Mains Road, Edinburgh
}

Received 30.vii.68

\section{INTRODUCTION}

FREQUENCY-DEPENDENT selection is capable of maintaining a balanced genetic polymorphism (Wright, 1948; Teissier, 1954; Li, 1962, Glarke and O'Donald, 1964). Under this system the selective values of genotypes are negatively related to their frequencies. It has been suggested that predators can exert frequency-dependent selection on their prey, even in the absence of mimetic resemblances between prey species. Cain and Sheppard (1954) first drew attention to this possibility, although the idea was adumbrated by Poulton (1890). It was not until 1962, however, that evidence came to light suggesting that the process does indeed occur (Clarke, 1962a). Predators apparently concentrate on one or a few common varieties of prey, and tend to overlook rarer forms even if they are obvious. By a process of learning the predators develop specific "searching images" for the varieties most frequently encountered (as suggested, in another context, by Tinbergen, 1960). Selection of this type has been described as apostatic because it involves the advantage of rare phenotypes that stand out from the norm. I have argued that it is an important factor in the evolution of diversity within and between species (Clarke, 1962a).

A study of the land snails (Cepaea nemoralis (L.) and Cepaea hortensis (Müll.) led me to suggest that their polymorphisms are maintained, at least in part, by apostatic selection (Clarke, 1962b). Carter (1967) has recently criticised some of my conclusions. In the present paper, I will bring up to date the evidence for apostatic selection, discuss its application to Cepaea, and reply to Carter's criticisms.

\section{The general evidence}

A belief in the importance of apostatic selection does not depend primarily upon studies of Cepaea. It is based on a knowledge of common features in the behaviour of predators, and strengthened by a consideration of the patterns of variation found in many non-mimetic colour polymorphisms.

The earlier evidence relating to the behaviour of predators has already been reviewed (Clarke, 1962a). What was lacking, however, at the time of this review was a clear demonstration (i) that avian predators were capable of forming searching images for the colour of their prey, and (ii) that wild birds could exert effective apostatic selection. These gaps have now been filled by the work of Groze (personal communication) on crows and by Allen (personal communication) and Allen and Clarke (1968) on various species of Passerines.

The work of Allen and Clarke (1968) is appropriate to this discussion. They offered artificial dimorphic prey (made of flour and lard, and coloured green or brown) to wild birds against uniform backgrounds of green grass or brown soil. Birds that had been offered only one colour for several days 
took the colour preferentially when both types were offered in equal proportions. Many individual birds showed an exclusive preference for the familiar colour (Allen, unpublished).

If, from these experiments, we conclude that the formation of a searching image for a particular colour depends upon several successive encounters with it, then in a polymorphic population the relative probability of forming a searching image for a common form should be greater than its frequency in the population, and for a rare form it should be less. Thus the likelihood of predation for any morph should be negatively related to its frequency. Experiments in which wild birds were offered green and brown baits in different proportions gave evidence that the relative predation did indeed vary in this way (Allen and Clarke, 1968). Recent work by Arnold (unpublished) has demonstrated a similar result when wild thrushes were offered two morphs of Cepaea nemoralis at different frequencies against uniform backgrounds of leaf-litter in beechwoods. These experiments show that predators can exert frequency-dependent selection on polymorphic prey under natural conditions.

The second line of evidence for apostatic selection is that it provides the most satisfactory explanation for the origin and maintenance of a wide range of non-mimetic colour polymorphisms (Clarke, 1962a). Many of the animals showing these polymorphisms are known to be attacked by predators that hunt by sight. In the absence of apostatic effects there should be strong visual selection towards the fixation of the more cryptic morphs. If the polymorphisms were maintained by selection unrelated to the visual properties of the morphs, then we would expect the visual selection to favour any mutants or modifiers tending to obscure the visible polymorphisms. In many cases, however, they are clear-cut and obvious, and in some we know that they have remained so for very long periods (Diver, 1929; Owen, 1966; Ewers, 1966).

It is possible, as Cain, King and Sheppard (1960) have suggested for Cepaea, that some morphs may be kept distinct because they resemble distinct components of the visible background on which the animals live. This form of selection would not, however, be frequency-dependent. Furthermore, even in Cepaea there are morphs that seem to stand out against all backgrounds (e.g. bright pinks, some forms of 00300). The same is true in other polymorphic organisms.

Moment (1962), commenting upon variation in the brittlestar Ophiopholis aculeata and the butterfly clam Donax variabilis, suggested that apostatic selection (which he called " reflexive selection") was the most satisfactory explanation for the origin and maintenance of their polymorphisms. Owen and Weigert (1962) argued the same for the spittle-bug Philaenus spumarius, as did Owen (1965) for the snail Limnicolaria martensiana.

\section{Apostatic selection in Cepaea}

In Britain, both species of Cepaea are subject to periodically heavy predation by thrushes (Cain and Sheppard, 1954; Goodhart, 1958; Clarke, 1960). This predation has been shown to be selective (Sheppard, 1951). Since thrushes appear to show strong searching images (Allen, unpublished), and since the polymorphisms are distinct and long standing, it is reasonable to conclude that apostatic selection has played a part in maintaining them. The work of Arnold, already mentioned, makes this conclusion virtually certain. 
When two sympatric species share the same predator, and when conditions are favourable to apostatic selection, the species should diverge in appearance (Clarke, 1962a, b). If the predator has a searching image for one species, selection on the other should favour variants that have the least likelihood of being confused with it. If both species are polymorphic, and if the polymorphisms are visually similar (as they are in C. nemoralis and C. hortensis), then we may expect that selection will act in one species against any variety that is common in the other. If, for example, yellow unbanded shells were particularly common in $C$. hortensis (because, perhaps, of selection unrelated to their visual properties) we would expect an unusually low frequency of visually similar forms in $C$. nemoralis. The properties of the background, and other selective effects of the environment, will determine what frequencies should be considered "unusually" high or low. A balance due to apostatic selection would influence but not prevent responses to the visual, or other, properties of the environment. Extreme habitats might produce high frequencies of the same phenotype in both species. In general, however, a series of visually similar but ecologically diverse habitats should exhibit negative relations between the frequencies of equivalent forms in the two species. Without apostatic effects we would expect a positive relation.

A series of samples taken from mixed colonies of $C$. nemoralis and $C$. hortensis within sixty miles of Oxford showed the results expected from apostatic selection (Clarke, 1962b). Among samples from open habitats (grasslands, rough herbage, fens) there was a significant negative correlation between the frequencies of yellow " effectively unbanded" shells in the two species $(P<0 \cdot 02)$. Among samples from woods there was a non-significant negative correlation $(\mathrm{P}<0 \cdot 1)$. Between the two classes there was, as expected, a positive relation.

Carter (1967) has criticised my suggestion that the negative correlations are due to the effects of apostatic selection. Carter's criticisms come into several categories and they will be discussed individually.

(i) He has pointed out that my data are heterogeneous, and that within the region studied particular areas show characteristic proportions of phenotypes in both species. The problem of heterogeneity was, however, acknowledged and discussed in my (1962b) paper. The important question is whether the heterogeneity has given rise to the negative correlations. The significant negative correlations found by Carter within some small areas (Uffington, Liddington West) show that it has not. In this respect he has confirmed my conclusions. The lack of significant negative correlations within other areas may be due to genuine differences from place to place, or to the fact that the numbers of samples were small. He found no positive correlations.

(ii) Carter argues that the negative correlations at Uffington and W. Liddington occur in areas where "visual selection for crypsis is ineffective", in other words where he found no obvious differences in phenotype-frequencies between woods and open habitats. In his tables for the W. Liddington area there are no records from woods (although I understand from $\mathrm{Dr}$ Carter that some were taken and that details will be published elsewhere). In the Uffington area there are records from three woods. All of these are, in fact, very mixed habitats with many herbaceous plants at ground level. The evidence is inconclusive.

Even if it is true that in these areas there is no separation between woods and open habitats, the hypothesis that the negative relations are due to 
apostatic selection is not excluded. Recent experiments on the behaviour of avian predators (Allen, personal communication) suggest that in some situations apostatic effects may be a good deal stronger than selection for crypsis.

(iii) Samples taken from unmixed colonies of C. hortensis at Woolstone, half a mile west of Uffington, show changes in the frequency of yellow unbanded that parallel those in mixed colonies at Uffington. Carter argues that there is some selective pressure bringing about a change in the frequency of unbanded hortensis regardless of the occurrence of nemoralis, because the distance between Uffington and Woolstone is too great to allow gene-flow to cause any similarity of morph-frequencies. The validity of this argument depends upon the assumption that there are no nemoralis between the two localities, or elsewhere in the vicinity of Woolstone. However, I have collected nemoralis in mixed colonies less than 200 yards from Carter's Woolstone samples, both to the east and to the west. Since the distribution of the species is patchy, and since these shells were taken in the course of other work, without a special search being made, it is likely that populations of nemoralis occur even nearer to Woolstone, well within the range of gene-flow, and

TABLE 1

The composition of samples from populations of $\mathrm{C}$. nemoralis in the vicinity of Woolstone Hill, Berks.

\begin{tabular}{|c|c|c|c|c|c|c|c|c|c|c|}
\hline Ordnance & \multicolumn{3}{|c|}{ Yellows } & \multicolumn{3}{|c|}{ Pinks } & & & & Position on scarp, \\
\hline $\begin{array}{l}\text { Survey } \\
\text { Grid }\end{array}$ & & & Other & & & Other & & & & $\begin{array}{l}\text { with distance and } \\
\text { direction from nearest }\end{array}$ \\
\hline Reference & 00300 & 00345 & banned & 00300 & 00345 & banned & Brown & Total & Y.E.U. & Woolstone sample \\
\hline J29658615 & 12 & 3 & 14 & 5 & 2 & 11 & — & 47 & $31 \cdot 9$ & Top Ca. $200 \mathrm{yc}$ \\
\hline U29758690 & 7 & 3 & 3 & 4 & 0 & 2 & 3 & 22 & $45 \cdot 5$ & High Ca. 400 yd. E \\
\hline UU29658725 & - & - & - & - & - & - & 1 & 1 & 0 & Bottom Ca. 200 yd. E \\
\hline
\end{tabular}

indeed near enough for them to share common predators with Carter's populations. Details of nemoralis in nearby samples for which scores are available are given in table 1 . The numbers are very small, but the data are consistent with a belief that the variation in nemoralis near Woolstone parallels the variation at Uffington (in other words, that there is a negative correlation between the two species).

(iv) Carter compares the frequencies of yellow " effectively unbanded" hortensis and yellow nemoralis in mixed colonies with the frequencies of these phenotypes in pairs of nearby unmixed colonies. He suggests that if the proportions of a given class of morphs were more dissimilar in mixed colonies than in adjacent pairs of unmixed colonies, then this would be evidence in favour of apostatic interaction. It is important to note that such a relation would only be expected if the mixed and unmixed colonies were roughly equivalent in other aspects of their ecology.

Carter presents his comparison graphically. He plots the proportions of yellow nemoralis on the abscissa of a scatter-diagram, and the proportions of yellow "effectively unbanded" hortensis on the ordinate. He then states, "The co-ordinates of greatest similarity of these two frequencies fall along the diagonal joining the two sets of co-ordinates ( 0 per cent., 0 per cent.) and (100 per cent., 100 per cent.). Lines drawn parallel to this diagonal represent equal degrees of similarity along their length, but the further they are away from the main diagonal, the more the degree of similarity that they represent 
decreases. . . In 12 of the 18 comparisons the yellow $C$. nemoralis and yellow effectively unbanded $C$. hortensis frequencies are more alike in the mixed than in the unmixed colonies. In five mixed colonies the frequencies are less alike, and in one comparison the frequencies are the same in the mixed and unmixed samples. In the absence of apostatic selection or any other interaction between the two species, there should be equal numbers of mixed colonies which are more alike and less alike than their respective unmixed colonies. The result obtained is not significantly different from this expectation $\chi_{(1)}^{2}=2 \cdot 65 \mathrm{P}<0 \cdot 1$."

I am grateful to Dr David Parkin for drawing my attention to the fact that Carter's "lines of similarity" are inappropriate. They should not be straight lines parallel to the main diagonal but a family of curves growing more convex as they depart from it. The difference between 5 per cent. and 15 per cent. is not proportionally the same as the difference between 45 per cent. and 55 per cent., and should not be treated as such. In fact, the lines of similarity should represent constant values of the cross-product ratio:

$\frac{\text { per cent. yellow in nemoralis } \times(100 \text {-per cent. yellow E.U. in hortensis })}{\text { per cent. yellow E.U. in hortensis } \times(100 \text {-per cent. yellow in nemoralis })}$.

When the lines are redrawn correctly, we find that in 13 out of the $18 \mathrm{com}$ parisons the frequencies are more alike in mixed colonies and in one comparison they are the same in mixed and unmixed. This is a statistically significant departure from the null hypothesis that there are equal numbers of mixed colonies that are more alike and less alike than their respective unmixed colonies $\left(\mathrm{P}=0.025^{*}\right)$. It indicates that the unmixed colonies are somehow qualitatively different from the mixed, and it invalidates the comparison as a test of apostatic interactions.

Among the five areas studied by Carter (Lambourn, Oxford-GoringChilterns, Uffington, Liddington E., Liddington W.) there are two that show significant negative correlations within habitat classes (Liddington W. open habitats, Uffington open habitats), one that shows a non-significant negative correlation (Oxford woods), two that show non-significant positive correlations (Oxford open habitats, Lambourn open habitats) and one in which the direction is difficult to interpret (Liddington E. open habitats). In all cases the numbers of samples are small, and we do not know if more intensive sampling would improve the non-significant correlations. The weight of evidence, however, is in favour of negative relations between the species. Carter provides no alternative explanation for these negative relations, and the simplest hypothesis is that they are the result of apostatic interactions. The recent experimental evidence for apostatic selection, reviewed at the beginning of this paper, adds strength to the conclusion. Of course, it remains possible that the simplest hypothesis is not the correct one, but at present there is no convincing evidence against it.

\section{Summary}

1. Experiments with wild birds indicate that they can exert frequencydependent selection on polymorphic prey under natural conditions.

* This is a one-tailed probability. Only deviations in one direction would invalidate the comparison. 
2. There is good evidence that polymorphic land snails of the genus Cepaea are subject to this apostatic selection.

3. In a series of ecologically similar mixed colonies of Cepaea nemoralis and Cepaea hortensis, there is a negative correlation between the frequencies of visually similar phenotypes in the two species. The correlation has been attributed to the effects of apostatic selection (Clarke, 1962b).

4. Carter (1967) has argued against this hypothesis. His arguments are reviewed and it is concluded that apostatic selection remains the most satisfactory explanation of the correlation.

Acknowledgments.--I am particularly grateful to Mr J. A. Allen and Dr R. W. Arnold for allowing me to quote their unpublished work. They have also, with Dr M. A. Carter and Dr J. D. Currey, very kindly read and criticised the manuscript. I am greatly indebted to the Science Research Council for financial support, and to Professors J. M. Mitchison and P. M. B. Walker for the help and facilities they have provided.

\section{References}

Allen, J. A., AND Clarke, B. 1968. Evidence for apostatic selection by wild Passerines. Nature, 220, 501-502.

CAIN, A. J., KING, J. M. B., AND SHEPPARD, P. M. 1960. New data on the genetics of polymorphism in the snail Cepaea nemoralis (L.). Genetics, 45, 393-411.

CAIN, A. J., AND ShEPpard, P. M. 1954. Natural selection in Cepaea. Genetics, 39, 89-116.

CARTER, M. A. 1967. Selection in mixed colonies of Cepaea nemoralis and Cepaea hortensis. Heredity, 22, 117-139.

CLARKE, B. 1960. Divergent effects of natural selection on two closely related polymorphic snails. Heredity, 14, 423-443.

CLARKE, B. 1962a. Balanced polymorphism and the diversity of sympatric species. In Taxonomy and Geography, ed. D. Nichols, Systematics Association, Oxford.

ClARKE, B. 1962 $b$. Natural selection in mixed populations of two polymorphic snails. Heredity, 17, 319-345.

Glarke, B., AND O'Donald, P. 1964. Frequency-dependent selection. Heredity, 19, 201-206. DIver, C. 1929. Fossil records of mendelian mutants. Nature, 124, 183.

EWERS, w. H. 1966. Polymorphism in fossil Velacumantus australis (Gastropoda: Potamididae). Aust. 7. Zool., 14, 867-875.

goodhart, c. B. 1958. Thrush predation in the snail Cepaea hortensis. 7. Anim. Ecol., 27, 47-58.

LI, c. c. 1962. On " reflexive selection". Science, 136, 1055.

MOMENT, G. B. 1962. Reflexive selection: a possible answer to an old puzzle. Science, 136, 262-263.

OWEN, D. F. 1965. A population study of an equatorial land snail Limnicolaria martensiana (Achatinidae). Proc. zool. Soc. Lond., 144, 361-382.

OWEN, D. F. 1966. Polymorphism in Pleistocene land snails. Science, 152, 71-72.

OWEN, D. F., AND WEIGERT, R. G. 1962. Balanced polymorphism in the meadow spittlebug, Philaenus spumarius. Am. Nat., 96, 353-359.

poulton, E. B. 1890. The Colours of Animals (2nd ed.). Kegan, Paul, Trench, Trüber and Co., London.

SHEPPARD, P. M. 1951. Fluctuations in the selective value of certain phenotypes in the polymorphic land snail Cepaea nemoralis (L.). Heredity, 5, 125-134.

TEISSIER, G. 1954. Conditions d'equilibre d'un couple d'allèles et supériorité des hétérozygotes. C.r. hebd. Séanc. Acad. Sci., Paris, 238, 621-623.

TINBERGEN, L. 1960. The natural control of insects in pinewoods. I. Factors influencing the intensity of predation by songbirds. Arch. Néerl. Zool., 13, 265-336.

WRIGHT, s. 1948. On the roles of directed and random changes in gene-frequency in the genetics of natural populations. Evolution, 2, 279-294. 